\title{
Uncertainty in river discharge observations: a quantitative analysis
}

\author{
G. Di Baldassarre ${ }^{1}$ and A. Montanari ${ }^{2}$ \\ ${ }^{1}$ Department of Hydroinformatics and Knowledge Management, UNESCO-IHE Institute for Water Education, \\ Delft, The Netherlands \\ ${ }^{2}$ Faculty of Engineering, University of Bologna, Bologna, Italy
}

Received: 31 October 2008 - Published in Hydrol. Earth Syst. Sci. Discuss.: 6 January 2009

Revised: 11 June 2009 - Accepted: 11 June 2009 - Published: 25 June 2009

\begin{abstract}
This study proposes a framework for analysing and quantifying the uncertainty of river flow data. Such uncertainty is often considered to be negligible with respect to other approximations affecting hydrological studies. Actually, given that river discharge data are usually obtained by means of the so-called rating curve method, a number of different sources of error affect the derived observations. These include: errors in measurements of river stage and discharge utilised to parameterise the rating curve, interpolation and extrapolation error of the rating curve, presence of unsteady flow conditions, and seasonal variations of the state of the vegetation (i.e. roughness). This study aims at analysing these sources of uncertainty using an original methodology. The novelty of the proposed framework lies in the estimation of rating curve uncertainty, which is based on hydraulic simulations. These latter are carried out on a reach of the Po River (Italy) by means of a one-dimensional (1-D) hydraulic model code (HEC-RAS). The results of the study show that errors in river flow data are indeed far from negligible.
\end{abstract}

\section{Introduction}

In recent years, there has been an increasing interest in assessing uncertainty in hydrology and analysing its possible effects on hydrological modelling (Montanari and Brath, 2004; Montanari and Grossi, 2008). Uncertainty has been recognised to be important in the communication with end users (Beven, 2006; Montanari, 2007) and to play a key role in the context of prediction in ungauged basins (PUB). Furthermore, uncertainty assessment is one of the key tasks of the PUB initiative launched in 2003 by the International Association of Hydrological Sciences (Sivapalan et al., 2003).

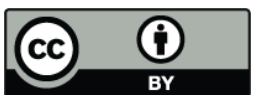

Correspondence to: G. Di Baldassarre (g.dibaldassarre@unesco-ihe.org)
Indeed, hydrologists are well aware that a significant approximation affects the output of hydrological models. Uncertainty is caused by many sources of error that propagate through the model therefore affecting its output. Three main sources of uncertainty have been identified by hydrologists (e.g. Goetzinger and Bardossy, 2008): (a) uncertainty in observations, which is the approximation in the observed hydrological variables used as input or calibration/validation data (e.g. rainfall, temperature and river); (b) parameter uncertainty, which is induced by imperfect calibration of hydrological models; (c) model structural uncertainty, which is originated by the inability of hydrological models to perfectly schematise the physical processes involved in the rainfall-runoff transformation. Among these, observation uncertainty is often believed to play a marginal role, given that it is often considered negligible with respect to (b) and (c). Hence, only few attempts have been made to quantify the effects of the observation uncertainty on hydrological and hydraulic modelling (e.g. Clarke (1999); Pappenberger et al., 2006). Nevertheless, the estimation of the uncertainty in observations with which the model is compared should be the starting point in model evaluation. For instance, the methodology recently proposed by Liu et al (2009) to assess model performance by using limits of acceptability (Beven, 2006) is based on the assessment of observation uncertainty.

Already 20 years ago, Pelletier (1987) reviewed 140 publications dealing with uncertainty in the determination of the river discharge, thereby providing an extensive summary. Pelletier (1987) referred to the case in which river discharge is measured by using the velocity-area method, which is based on the relationship:

$Q^{\prime}(x, t)=A(x, t) \times v(x, t)$

where $x$ is the river chainage, $t$ is the sampling time, $Q^{\prime}(x, t)$ is the measured river discharge, $A(x, t)$ is the cross sectional area and $v(x, t)$ is the average flow velocity. Hence, errors in $Q^{\prime}(x, t)$ are originated by uncertainties in both $A(x, t)$ and

Published by Copernicus Publications on behalf of the European Geosciences Union. 
$v(x, t)$, which are due to imprecision of the current meter, variability of the river flow velocity over the cross section and uncertainty in the estimation of the cross section geometry. Pelletier (1987) highlighted that the overall uncertainty in a single determination of river discharge, at the $95 \%$ confidence level, can vary in the range $8 \%-20 \%$, mainly depending on the exposure time of the current meter, the number of sampling points where the velocity is measured and the value of $v(x, t)$. Other contributions reported errors around 5-6\% (Leonard et al., 2000; Shmidt, 2002). In addition, the European ISO EN Rule 748 (1997) describes a methodology to quantify the expected errors of the velocity-area method.

It is important to note that, in operational practice, river discharge observations are usually obtained by means of the so-called rating curve method (e.g. World Meteorological Organisation, 1994). According to this technique, measurements of river stage are converted into river discharge by means of a function (rating curve), which is preliminarily estimated by using a set of stage and flow measurements. Hence, an additional error is induced by the imperfect estimation of the rating curve. In this paper, the river discharge estimated through the rating curve method is denoted by the symbol $Q(x, t)$.

This study aims at proposing a framework for assessing the global uncertainty affecting $Q(x, t)$, which obviously depends on the specific test site considered. In particular, approaches described by previous studies (e.g. Herschy, 1970, 1975; European ISO EN Rule 748, 1997) are applied to estimate the uncertainty of $Q^{\prime}(x, t)$ (velocity-area method), while an original methodology is developed to analyse additional sources of error in the river discharge observation, $Q(x, t)$, related to the uncertain estimation of the rating curve.

\section{Uncertainty in river discharge observations}

A full comprehension of the uncertainty that affects the rating curve method for discharge measurement requires a description of the procedure itself. In order to estimate the rating curve, field campaigns are carried out to record contemporaneous measurements of river stage $h(x, t)$ and river discharge $Q^{\prime}(x, t)$, evaluated by using the velocity-area method. These measurements allow the identification of a number of points $\left(Q^{\prime}(x, t) ; h(x, t)\right)$ that are then interpolated by using an analytical relationship as rating curve. Once the rating curve is estimated, the observed river discharge $Q(x, t)$ at arbitrary time $t$ can be operationally obtained by measuring the river stage $h(x, t)$. A function widely used as rating curve in river hydraulics (characterised by some physical justifications) is the power function (e.g. Dymond and Christian, 1982; Herschy, 1978; Pappenberger et al., 2006):

$Q(x, t)=c_{1} \times\left(h(x, t)-c_{2}\right)^{c_{3}}$ where $c_{1}, c_{2}$ and $c_{3}$ are calibration parameters, usually estimated by means of the least squares method (e.g. PetersenØverleir, 2004). Polynomial functions can also be used as rating curves (e.g. Yu, 2000):

$Q(x, t)=c_{1} \times h(\mathrm{x}, t)+c_{2} \times h(x, t)^{2}+c_{3} \times h(x, t)^{3}$

Obviously, in order to estimate a reliable rating curve, the reduction of the uncertainty of the measurements $Q^{\prime}(x, t)$ is required. The European ISO EN Rule 748 (1997) provides guidelines to this end by establishing an international standard for Europe. Accordingly, the measurement of $Q^{\prime}(x, t)$ should be carried out as follows. First of all one should measure the river flow velocity along a number of vertical segments lying on the cross section. When the cross section width exceeds $10 \mathrm{~m}, v(x, t)$ should be measured along at least 20 verticals that should be placed so that the river discharge in each subsection is less than 5\% of the total; the number and spacing of the velocity measurements along each vertical should be selected so that the difference in readings between two adjacent points is no more than $20 \%$ of the higher value. Once the velocity readings along each vertical are integrated over depth, the area of the obtained velocity curve gives the discharge per unit width along that vertical. The average of two subsequent area values gives the discharge per unit width in the subsection encompassed by the two verticals. Finally, the river discharge $Q^{\prime}(x, t)$ is obtained by integrating the discharges in each subsection.

\subsection{A simple model for the error structure of the rating curve method}

In order to infer the error affecting river flow observations derived by the rating curve method, a model for the error structure is to be introduced. Given that the available information is often limited in practical cases, a simple model is proposed herein. The model aims at taking into account the main sources of uncertainty within a simplified approach.

In this study, the uncertainty induced by imperfect observation of the river stage is neglected. This is consistent with the fact that these errors are usually very small (around 1-2 cm; e.g. Shmidt, 2002; Pappenberger et al., 2006) and therefore of the same order of magnitude as standard topographic errors. Moreover, the geometry of the river is assumed to be stationary, which means that the rating curve changes in time only because of seasonal variation of roughness (see below). This assumption has been made because the uncertainty induced by possible variations of the river geometry is heavily dependent on the considered case study and no general rule can be suggested. However, it is worth noting that, using this assumption, the study neglects one of the most relevant sources of uncertainty that may affect river discharge observations where relevant sediment transport and erosion processes are present.

In view of the assumptions made, the following main sources of error affecting $Q(x, t)$ can be identified: 1$)$ 
error $\varepsilon_{1}(Q(x, t))$ in the measurement $Q^{\prime}(x, t)$ obtained with the velocity-area method; 2) error $\varepsilon_{2}(Q(x, t))$ due to rating curve uncertainty which in turn is induced by 2.1) interpolation and extrapolation error, $\varepsilon_{2.1}(Q(x, t))$, of the rating curve; 2.2) the presence of unsteady flow conditions, $\varepsilon_{2.2}(Q(x, t))$; 2.3) seasonal changes of roughness, $\varepsilon_{2.3}(Q(x, t))$. According to operational experience, $\varepsilon_{1}(Q(x, t))$ and $\varepsilon_{2}(Q(x, t))$ are independent. This study assumes that the global uncertainty, $\varepsilon(Q(x, t))$, affecting $Q(x, t)$ can be obtained by:

$\varepsilon(Q(x, t))=\varepsilon_{1}(Q(x, t))+\varepsilon_{2}(Q(x, t))$

$\varepsilon_{1}(Q(x, t))$ is assumed to be a Gaussian random variable (e.g. European ISO EN Rule 748,1997$)$ while $\varepsilon_{2}(Q(x, t))$ is precautionarily assumed to be a binary random variable (see Sect. 2.3 below for more details) inferred by means of numerical simulations.

Traditional approaches are used in this study to infer $\varepsilon_{1}(Q(x, t))$, while original techniques are developed to evaluate the rating curve uncertainty $\varepsilon_{2}(Q(x, t))$. The latter is a difficult task as the methodology depends on the available information. As a general framework, the study proposes the estimation of $\varepsilon_{2}(Q(x, t))$ using a flood propagation model, under a set of simplifying assumptions. Some of these assumptions can be easily removed in practical applications, depending on the scope of the analysis and the available information. The proposed procedures for estimating $\varepsilon_{1}(Q(x, t))$ and $\varepsilon_{2}(Q(x, t))$ are described below.

\subsection{Uncertainty in river discharge measurements}

The uncertainty affecting the $Q^{\prime}(x, t)$ measurements derived by the velocity-area method is mainly due to: the river flow during the measurement may be unsteady; the presence of wind may affect the reliability of the velocity measurement; the velocity measurement by the current meter may be imprecise even in ideal conditions; the measurement of the width, $B$, of the cross section and water depth, $h_{i}$, along each $i$-th vertical segment may be affected by errors; the spatial variability of the flow velocity may induce estimation errors for the area of the velocity curve along the vertical segments and the mean velocity per unit width. This latter error is strictly related to the number of vertical segments.

In order to quantify the uncertainty affecting $Q^{\prime}(x, t)$ one needs to quantify the individual sources of error. The European ISO EN Rule 748 (1997) provides indications about the magnitude of these errors, at the $95 \%$ conFIdence level: the uncertainty $X_{e}$ affecting the measurement of the local flow velocity is about $\pm 6 \%$, when the velocity itself is about $0.5 \mathrm{~m} / \mathrm{s}$ and the exposure time is $2 \mathrm{~min}$; the uncertainty $X_{c}$ affecting the rating of the rotating element of the currentmeter is about $\pm 1 \%$, when the flow velocity is about $0.5 \mathrm{~m} / \mathrm{s}$; the uncertainty $X_{B}$ affecting the measurement of $B$ is about $\pm 1 \%$; the uncertainty $X_{d}$ affecting the measurement of $h_{i}$ is about $\pm 1 \%$; the uncertainty $X_{p}$ in the estimation of the mean velocity along each vertical segment is about $\pm 5 \%$ when at least 5 point measurements are collected; the uncertainty $X_{A}$ in the estimation of the mean velocity over the cross section is about $\pm 5 \%$ when the number of vertical segments, $m$, is about 20 .

The uncertainty affecting $Q^{\prime}(x, t)$ can be obtained by integrating the individual sources of uncertainty above (Herschy (1970, 1975); European ISO EN Rule 748, 1997). In particular under the assumptions that: i) the current meter is operated in ideal conditions, without any systematic uncertainty and in absence of significant wind and unsteady flow; ii) the errors are independent and normally distributed and iii) the number of vertical segments, is at least 20 , with an even distribution of discharge along the river cross subsections, the uncertainty affecting $Q^{\prime}(x, t)$, at the $95 \%$ confidence level, can be computed as:

$X_{Q}^{\prime}= \pm \sqrt{X_{A}^{2}+\frac{1}{m}\left(X_{e}^{2}+X_{c}^{2}+X_{B}^{2}+X_{d}^{2}+X_{p}^{2}\right)}=5.3 \%$

Thus, it can be concluded that any river discharge measurement that is used to calibrate a rating curve is affected by an uncertainty of about $5 \%$ of $Q^{\prime}(x, t)$ at the $95 \%$ confidence level. This outcome matches the indications reported in Leonard et al. (2000) and Shmidt (2002). It follows that $\varepsilon_{1}(Q(x, t))$ is a Gaussian random variable with zero mean and standard deviation equal to $0.027 Q(x, t)$.

\subsection{Rating curve uncertainty}

This study assumes that in the operational practice no information is available to infer the sign of the errors $\varepsilon_{2.1}(Q(x, t)), \varepsilon_{2.2}(Q(x, t))$ and $\varepsilon_{2.3}(Q(x, t))$. In fact, even though one could infer the sign of the error induced by unsteady flow and roughness changes, the necessary information is often not available. Moreover, it is unlikely to introduce any reliable assumption about the sign of the errors induced by interpolation/extrapolation. The worst situation is obtained when the signs are in agreement; in fact, if the errors have opposite signs there is error compensation. Therefore, in order to follow a conservative approach, these errors are assumed to have an absolute additive structure, so that the absolute error affecting $Q(x, t)$, which is induced by rating curve uncertainty, $\left|\varepsilon_{2}(Q(x, t))\right|$, can be obtained by:

$$
\begin{aligned}
& \left|\varepsilon_{2}(Q(x, t))\right|= \\
& \left|\varepsilon_{2.1}(Q(x, t))\right|+\left|\varepsilon_{2.2}(Q(x, t))\right|+\left|\varepsilon_{2.3}(Q(x, t))\right|
\end{aligned}
$$

This allows one to deterministically obtain a safe estimate of the absolute error induced by rating curve uncertainty via numerical simulation (see below). However, given that no information is available in operational practice to infer the error sign, $\varepsilon_{2}(Q(x, t))$ is assumed to be a binary random variable which can assume the values $+\left|\varepsilon_{2}(Q(x, t))\right|$ and $-\left|\varepsilon_{2}(Q(x, t))\right|$ with equal probability. 


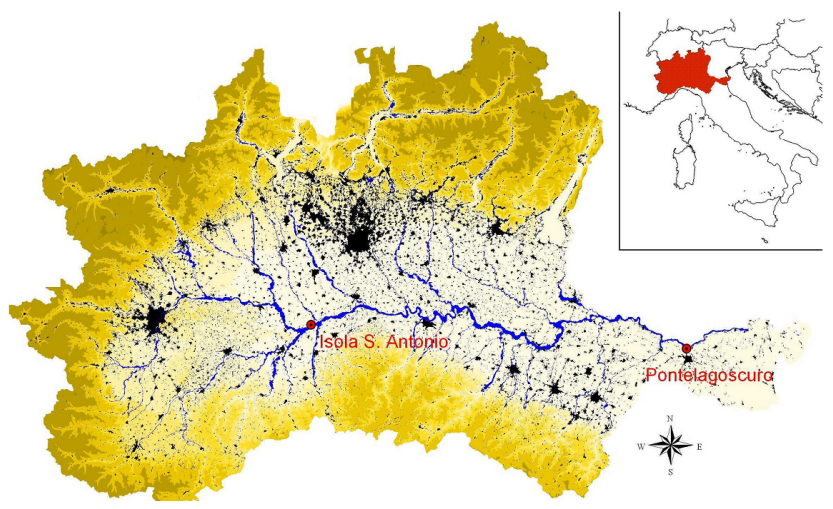

Fig. 1. The Po River basin and the river reach under study from Isola Sant'Antonio to Pontelagoscuro (blue); altimetry of the catchment (yellow scale).

Table 1. Geometric characteristics of the Po River reach from Isola S. Antonio to Pontelagoscuro.

\begin{tabular}{lc}
\hline Main channel width $(\mathrm{m})$ & $200-500$ \\
\hline Main channel depth $(\mathrm{m})$ & $10-15$ \\
Floodplain width $(\mathrm{m})$ & $1000-3000$ \\
Average bed slope $(\%)$ & 0.02 \\
\hline
\end{tabular}

As mentioned above, in order to quantify $\left|\varepsilon_{2}(Q(x, t))\right|$ numerical experiments were performed using the 1-D model code HEC-RAS (Hydrologic Engineering Center, 2001). HEC-RAS solves the 1-D differential equations for unsteady open channel flow (De Saint Venant equations), using the finite difference method and a four point implicit method (box scheme; Preismann, 1961). HEC-RAS is widely used for hydraulic modelling (e.g. Pappenberger et al., 2006; Young et al., 2009; Di Baldassarre et al., 2009) and a number of studies have showed that HEC-RAS is often suitable for providing a reliable reproduction of the flood propagation in natural rivers and streams (e.g. Horritt and Bates, 2002; Castellarin et al. 2009).

The numerical study focused on a $330 \mathrm{~km}$ reach of the Po River from Isola Sant'Antonio to Pontelagoscuro (see Fig. 1). The Po River is the longest river in Italy (the total length is about $652 \mathrm{~km}$ ) and it drains a large part of northern Italy, with a contributing area at the closure section of about $70000 \mathrm{~km}^{2}$. The geometry of river reach was described by 275 cross sections surveyed in 2005. Figure 2 shows the elevation of the river bed and the levee system. The main geometric characteristics of the reach are summarised in Table 1. In October 2000 a major flood event occurred along the Po River, with an estimated peak flow of about $10500 \mathrm{~m}^{3} / \mathrm{s}$ at Isola Sant'Antonio and $9800 \mathrm{~m}^{3} / \mathrm{s}$ at Pontelagoscuro. River stage observations collected during the 2000 flood were used to calibrate the 1-D model. In
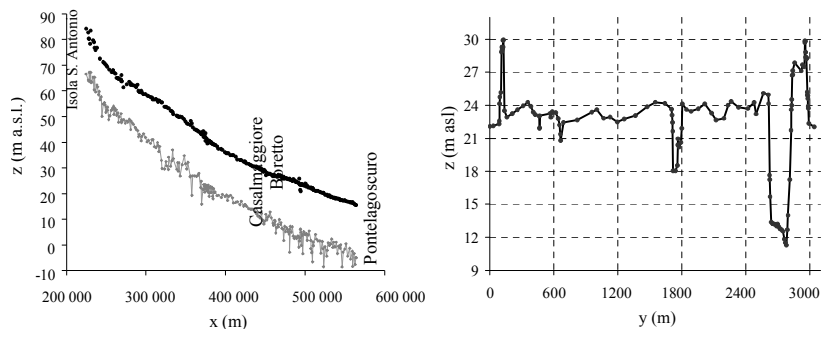

Fig. 2. Levee system (black) and bed (grey) elevation of Po River from Isola Sant'Antonio to Pontelagoscuro and location of Casalmaggiore and Boretto [left panel]; example of cross section near Boretto[right panel].

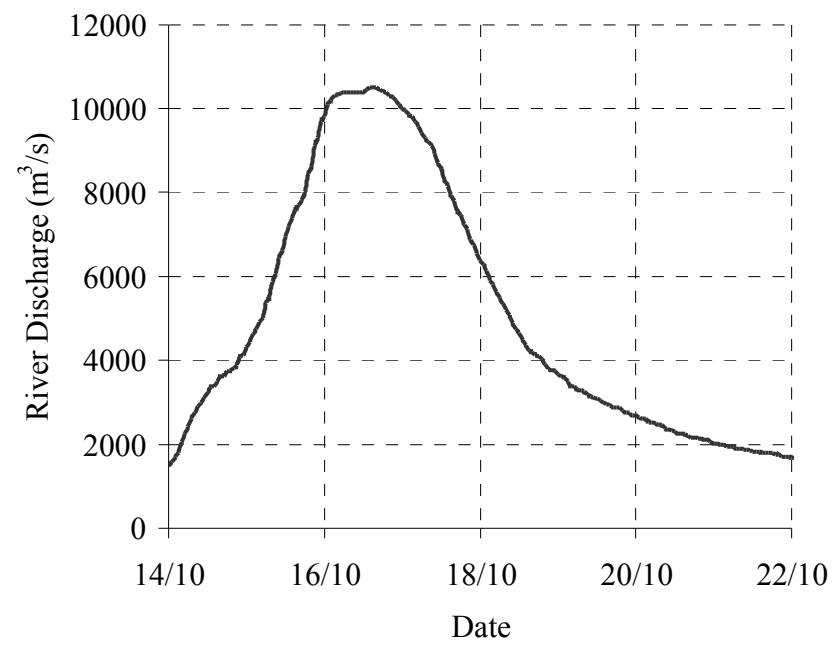

Fig. 3. October 2000 flood event: discharge hydrograph at Isola Sant'Antonio used as upstream boundary condition.

particular, the Manning roughness coefficient was allowed to vary between 0.01 and $0.06 \mathrm{~m}^{-1 / 3} \mathrm{~s}$ for the main channel and between 0.05 and $0.15 \mathrm{~m}^{-1 / 3} \mathrm{~s}$ for the floodplain. Several simulations of the 2000 flood event were carried out by using: the flow hydrograph observed at Isola S. Antonio as upstream boundary condition (Fig. 3), the flow hydrograph recorded in the major tributaries as lateral inflow and the stage hydrograph observed at Pontelagoscuro as downstream boundary condition.

To check the model reliability, the water stages observed in two internal cross sections (Casalmaggiore and Boretto, Fig. 2) were compared to simulated ones. The best performance was obtained by using Manning's values equal to $0.03 \mathrm{~m}^{-1 / 3} \mathrm{~s}$ for the main channel and $0.09 \mathrm{~m}^{-1 / 3} \mathrm{~s}$ for the floodplain. These values agree with what is recommended by the literature. In particular, Chow et al. (1988) suggest for this type of rivers Manning coefficients around 0.03$0.04 \mathrm{~m}^{-1 / 3} \mathrm{~s}$ for main channel and around $0.08-0.12 \mathrm{~m}^{-1 / 3} \mathrm{~s}$ and floodplain. Figure 4 shows the simulated and observed stage hydrographs in the two internal cross sections. By 

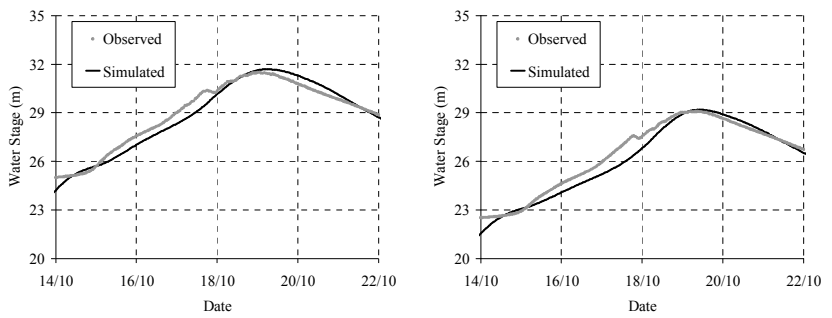

Fig. 4. Model calibration: observed (grey dots) and simulated (black line) stage hydrographs in Casalmaggiore [left panel] and Boretto [right panel].

analysing Fig. 4, one can observe that the model provides a satisfactory reproduction of the hydraulic behaviour of the reach under study, although it does not capture irregularities on the rising limb. These irregularities are mainly due to the presence of some two-dimensional (2-D) features, such as failures of minor levees, which cannot be represented using a 1-D model.

In order to inspect the uncertainty induced by an imperfect estimation of the rating curve, the study focused on 17 cross sections placed near the internal cross section of Boretto. For each of them the 1-D model was used to estimate the steady flow rating curve for river discharges ranging from 1000 to $12000 \mathrm{~m}^{3} / \mathrm{s}$. It is relevant to note that in the river reach under study there is in practice a one-to-one correspondence between the water stage and the river discharge in steady flow conditions, in view of the negligible role played by the downstream disturbances and boundary condition.

\subsubsection{Uncertainty induced by interpolating and extrap- olating the rating curve}

The interpolation and extrapolation error $\left|\varepsilon_{2.1}(Q(x, t))\right|$ was estimated as follows. For each cross section, a total of $11\left(Q^{\prime}(x, t) ; h(x, t)\right)$ points corresponding to river discharge values in the range $1000-6000 \mathrm{~m}^{3} / \mathrm{s}$, by steps of $500 \mathrm{~m}^{3} / \mathrm{s}$, were obtained through steady flow simulations. Then, rating curves were estimated using the two Eqs. (2) and (3) to interpolate these $\left(Q^{\prime}(x, t) ; h(x, t)\right)$ points. This methodology reflects the fact that rating curves are usually derived by using river discharge measurements related to ordinary flow conditions (for obvious practical reasons) and then extrapolated to estimate river discharge for high flow conditions also. Specifically, in the river reach under study, river discharges in the range $1000-6000 \mathrm{~m}^{3} / \mathrm{s}$ correspond to ordinary flow conditions (from low flow values to ordinary floods), while river discharges in the range $6500-12000 \mathrm{~m}^{3} / \mathrm{s}$ correspond to exceptional flow conditions (from about 1-in-5 to 1-in-100 year floods; e.g. Maione et al., 2003). Finally, for each cross section, errors were computed by comparing the steady flow rating curve to the estimated one both in the ranges $1000-6000 \mathrm{~m}^{3} / \mathrm{s}$, interpolation error, and 6500 $12000 \mathrm{~m}^{3} / \mathrm{s}$, extrapolation error (e.g. Fig. 5). The error anal-

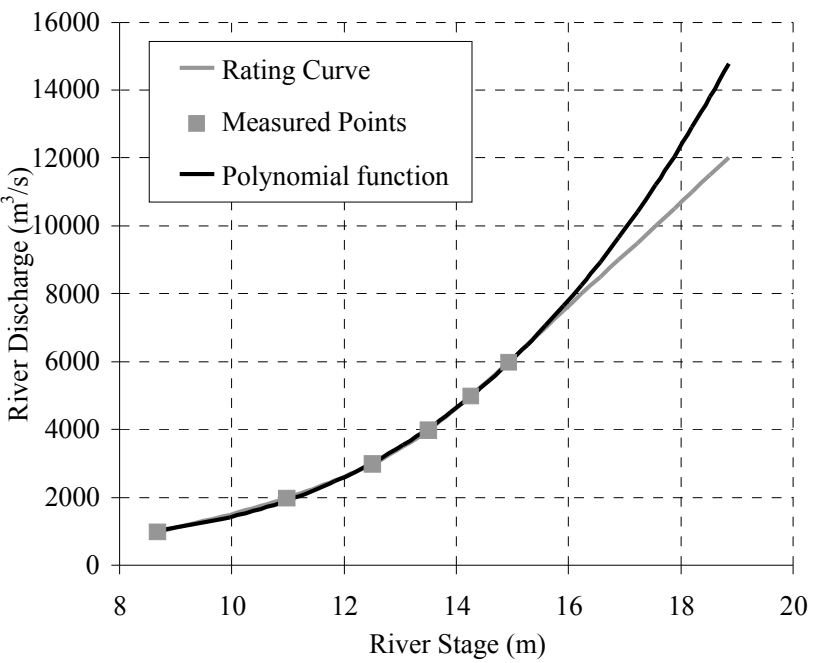

Fig. 5. Steady flow rating curve (grey line) and estimated rating curve (black line) using measured points (grey dots) in the range $1000-6000 \mathrm{~m}^{3} / \mathrm{s}$.

ysis pointed out that the polynomial function (3) performs slightly better than the power function (2). Specifically, using the polynomial function (3) as rating curve and assuming that the percentage errors with respect to $Q(x, t)$ are Gaussian, the average $\left|\varepsilon_{2.1}(Q(x, t))\right|$ along the river reach was found to be equal to $1.2 \%$ and $11.5 \%$ of $Q(x, t)$, at the $95 \%$ confidence level, for the interpolation and extrapolation error, respectively; (whereas, using the power function (2) as rating curve, the average $\left|\varepsilon_{2.1}(Q(x, t))\right|$ along the river reach was found to be equal to $1.7 \%$ and $13.8 \%$ of $Q(x, t)$. Table 2 reports the percentage values of this source of uncertainty for each considered $Q(x, t)$ value. By analysing Table 2 one can observe that, as expected, errors increase for increasing river discharge.

\subsubsection{Uncertainty induced by the presence of unsteady flow conditions}

It is well known that in unsteady flow conditions there is not a one-to-one relationship between the river stage and the river discharge (e.g. Dottori et al., 2009). Actually, during a flood the same river stage corresponds to different river discharges in the two limbs of the hydrograph, the higher one occurring in the raising limb. In order to assess the magnitude of the error that can be induced by the presence of unsteady flow, the model was used to simulate the 2000 flood event and estimate the unsteady flow rating curve (Fig. 6). Then, for each cross section, river discharge values simulated by the model were compared to the corresponding values estimated by using the steady flow rating curve (Fig. 6). For each value of $Q(x, t)$ in the range $1000-12000 \mathrm{~m}^{3} / \mathrm{s}$, with step of $500 \mathrm{~m}^{3} / \mathrm{s}$, and each cross section the largest absolute errors were taken in order to obtain a one-to-one relationship 
Table 2. Average values, expressed as percentage of $Q(x, t)$, of the three single sources of rating curve uncertainty $\left(\left|\varepsilon_{2.1}\right|,\left|\varepsilon_{2.2}\right|\right.$, $\left.\left|\varepsilon_{2.3}\right|\right)$ for the considered discrete values of the river discharge; upper and lower $95 \%$ confidence band for $Q(x, t)$, averaged over the river reach, along with the average value of $\varepsilon^{*}(Q(x, t))$ expressed as percentage of $Q(x, t)$. Note that $\varepsilon_{1}(Q(x, t))$ is uniformly equal to $4.4 \%$ of the observed discharge at the $95 \%$ confidence level.

\begin{tabular}{rrrrrrr}
\hline$Q(x, t)$ & $\left|\varepsilon_{2.1}\right|$ & $\left|\varepsilon_{2.2}\right|$ & $\left|\varepsilon_{2.3}\right|$ & $Q_{95 \%}^{+}(x, t)$ & $Q_{95 \%}^{-}(x, t)$ & $\varepsilon^{*}(Q(x, t))$ \\
\hline 1000 & 1.8 & 0.0 & 0.0 & 938 & 1062 & 6.2 \\
1500 & 4.1 & 1.2 & 0.3 & 1350 & 1650 & 10.0 \\
2000 & 2.8 & 2.4 & 0.5 & 1798 & 2202 & 10.1 \\
2500 & 0.4 & 3.6 & 0.9 & 2268 & 2733 & 9.3 \\
3000 & 1.2 & 4.9 & 1.6 & 2637 & 3363 & 12.1 \\
3500 & 1.2 & 6.1 & 2.5 & 3003 & 3997 & 14.2 \\
4000 & 0.7 & 9.7 & 3.4 & 3272 & 4728 & 18.2 \\
4500 & 0.2 & 13.2 & 4.3 & 3506 & 5495 & 22.1 \\
5000 & 0.4 & 14.9 & 5.1 & 3760 & 6240 & 24.8 \\
5500 & 0.5 & 16.2 & 5.6 & 4032 & 6969 & 26.7 \\
6000 & 0.1 & 17.1 & 6.0 & 4344 & 7656 & 27.6 \\
6500 & 0.5 & 17.2 & 6.3 & 4654 & 8346 & 28.4 \\
7000 & 1.6 & 17.2 & 6.6 & 4914 & 9086 & 29.8 \\
7500 & 3.1 & 16.5 & 6.7 & 5198 & 9803 & 30.7 \\
8000 & 4.7 & 15.3 & 6.8 & 5504 & 10496 & 31.2 \\
8500 & 6.8 & 13.7 & 6.9 & 5797 & 11203 & 31.8 \\
9000 & 9.2 & 11.5 & 6.9 & 6120 & 11880 & 32.0 \\
9500 & 11.8 & 10.3 & 6.9 & 6327 & 12673 & 33.4 \\
10000 & 14.4 & 10.0 & 7.0 & 6420 & 13580 & 35.8 \\
10500 & 17.2 & 7.2 & 7.0 & 6741 & 14259 & 35.8 \\
11000 & 19.9 & 5.7 & 7.0 & 6930 & 15070 & 37.0 \\
11500 & 23.0 & 5.5 & 7.0 & 6912 & 16089 & 39.9 \\
12000 & 26.0 & 5.3 & 7.1 & 6864 & 17136 & 42.8 \\
\hline
\end{tabular}

between $\left|\varepsilon_{2.2}(Q(x, t))\right|$ and $Q(x, t)$. By assuming that the percentage (with respect to $Q(x, t))\left|\varepsilon_{2.2}(Q(x, t))\right|$ are Gaussian, the average $\left|\varepsilon_{2.2}(Q(x, t))\right|$ along the river reach was found to be equal to $9.8 \%$ of $Q(x, t)$, at the $95 \%$ confidence level. Table 2 reports the percentage values of this source of uncertainty for each considered $Q(x, t)$ value. By analysing Table 2 one can observe that errors are particularly high for intermediate river discharge values.

\subsubsection{Uncertainty induced by seasonal changes of the river roughness}

Floodplain roughness depends on the state of the vegetation, which is affected by seasonal variations. This causes changes in the rating curve and therefore may affect the river discharge estimation (Franchini et al., 1999). The Po River is characterised by floodplains largely abandoned or covered by broad leaved woods. Figure 7 shows two rating curves for one cross section along the Po River calculated by the 1-D model. They refer to values of the Manning floodplain coefficient equal to $0.09 \mathrm{~m}^{-1 / 3} \mathrm{~s}$ and $0.12 \mathrm{~m}^{-1 / 3} \mathrm{~s}$. The former is the calibrated value, which refers to October (when the 2000 flood event occurred). The latter is a value that might be representative of Spring conditions, according to Chow

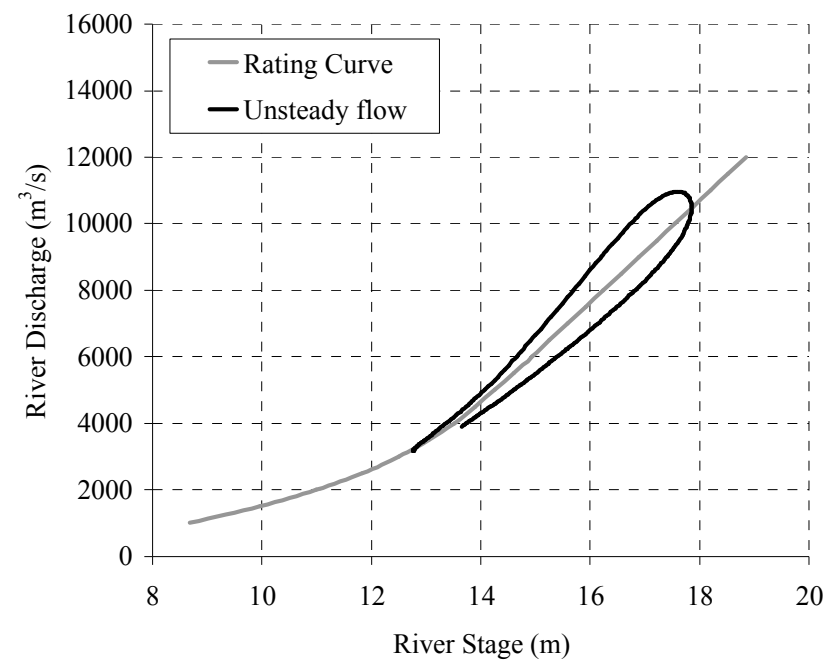

Fig. 6. Steady flow rating curve (grey) and unsteady flow rating curve (black).

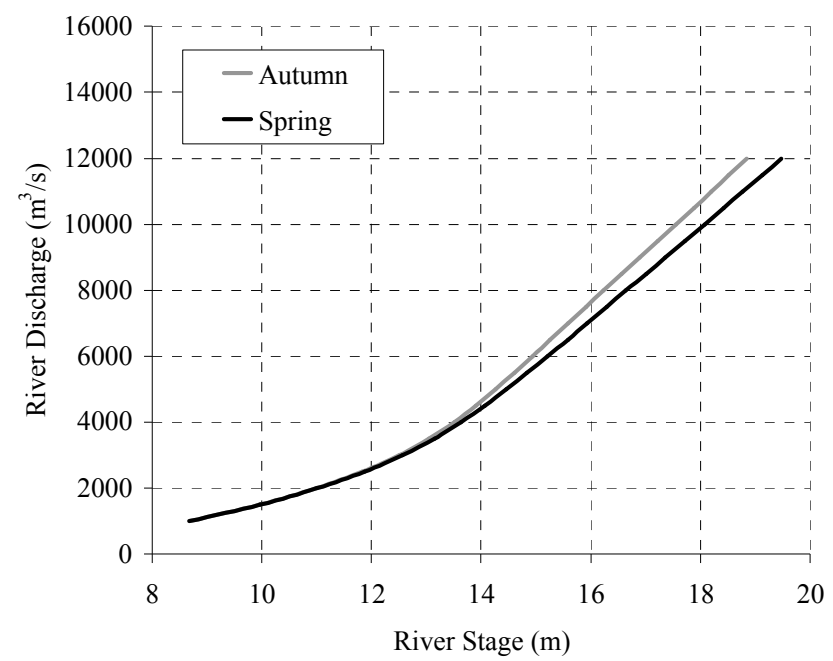

Fig. 7. Steady flow rating curves for different values of the Manning's floodplain coefficient $\left(0.09 \mathrm{~m}^{-1 / 3} \mathrm{~s}\right.$ for the Autumn curve and $0.12 \mathrm{~m}^{-1 / 3} \mathrm{~s}$ for the Spring curve).

et al. (1988). For each value of $Q(x, t)$ in the range 1000 $12000 \mathrm{~m}^{3} / \mathrm{s}$, with step of $500 \mathrm{~m}^{3} / \mathrm{s}$, and each cross section, the error $\varepsilon_{2.3}(Q(x, t))$ was computed. By assuming that the percentage (with respect to $Q(x, t)) \varepsilon_{2.3}(Q(x, t))$ are Gaussian the average of $\left|\varepsilon_{2.3}(Q(x, t))\right|$ was found to be equal to $4.9 \%$ of $Q(x, t)$, at the $95 \%$ confidence level. Table 2 reports the percentage values of this source of uncertainty for each considered $Q(x, t)$ value. By analysing Table 2 one can observe that, as expected, this source of error increases for increasing river discharge. 


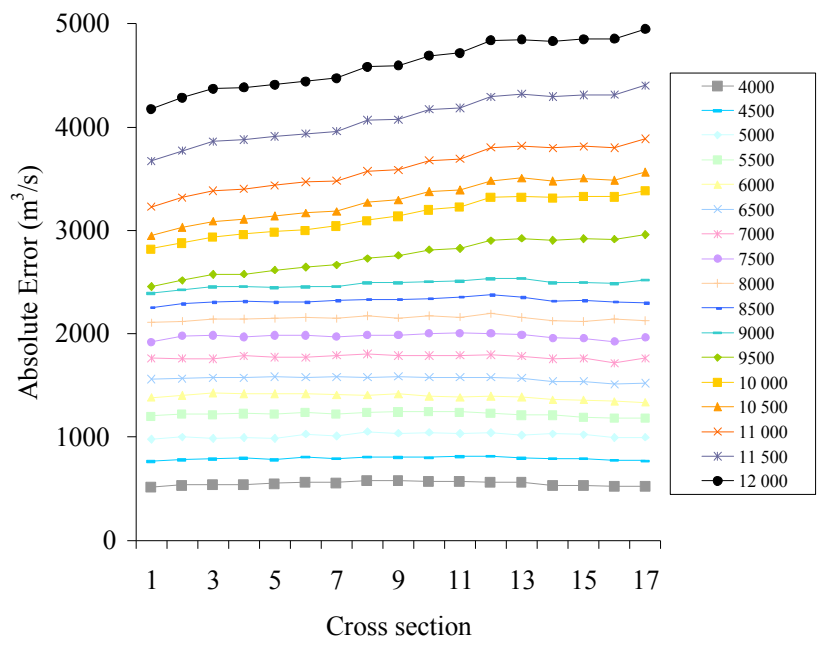

Fig. 8. Estimated $\left|\varepsilon_{2}(Q(x, t))\right|$ in the 17 cross sections for different river discharge values (see legend, values in $\mathrm{m}^{3} / \mathrm{s}$ ).

\subsubsection{Computation of the total rating curve uncertainty}

The total rating curve uncertainty was evaluated by summing up, through Eq. (6), the errors induced by: 1) interpolation and extrapolation of river discharge measurements; 2) presence of unsteady flow; 3) seasonal variation of roughness. Figure 8 reports the progress of $\left|\varepsilon_{2}(Q(x, t))\right|$ along the river reach for different values of $Q(x, t)$. Figure 8 clearly shows that errors increase, when the river discharge increases. In percentage terms, $\left|\varepsilon_{2}(Q(x, t))\right|$ varies from $1.8 \%$ to $38.4 \%$ of $Q(x, t)$, with a mean value of $21.2 \%$ and a standard deviation of $10.8 \%$.

\subsection{Computation of the global uncertainty}

Under the aforementioned assumption of independence of $\varepsilon_{1}(Q(x, t))$ and $\varepsilon_{2}(Q(x, t))$, the global error affecting $Q(x, t), \varepsilon(Q(x, t))$, at the $95 \%$ confidence level, can be computed according to Eq. (4). It has to be taken into account that $\varepsilon_{1}(Q(x, t))$ is a Gaussian random variable with zero mean and standard deviation equal to $0.027 Q(x, t)$ (see Sect. 2.2) while $\varepsilon_{2}(Q(x, t))$ is a binary random variable taking the values $+\left|\varepsilon_{2}(Q(x, t))\right|$ and $-\left|\varepsilon_{2}(Q(x, t))\right|$ with equal probability. Its absolute value was computed above and is visualised in Fig. 8 for discrete values of $x$ and $Q$. Therefore, the $95 \%$ confidence bands of an assigned $Q(x, t)$ value can be computed with the relationship:

$$
\begin{aligned}
& Q(x, t) \pm\left\{\alpha \times 0.027 Q(x, t)+\left|\varepsilon_{2}(Q(x, t))\right|\right\}= \\
& Q(x, t) \pm \varepsilon^{*}(Q(x, t))
\end{aligned}
$$

where $\alpha$ is the 0.95 quantile for the standard normal distribution (equal to 1.645) and $\varepsilon^{*}(Q(x, t))$ is the width of the $95 \%$ upper (and lower) confidence band. Table 2 shows the aver- age value, along the river reach, of the upper and lower confidence band for the considered discrete values of the river discharge, along with the average value of $\varepsilon^{*}(Q(x, t))$, expressed as percentage of $Q(x, t)$. By analysing Table 2 one can observe that, in the Po River reach under study, the estimation of river discharge using the rating curve method is affected by an increasing error for increasing river discharge values. At the $95 \%$ confidence level the error ranges from $6.2 \%$ to $42.8 \%$ of $Q(x, t)$, with an average value of $25.6 \%$.

\section{Discussion}

The error models used above to compute $\varepsilon(Q(x, t))$ was derived by introducing a series of assumptions. The most important ones are summarised here below:

1. the uncertainty induced by imperfect measurement of the river stage is negligible;

2. the geometry of the river cross sections is stationary in time;

3. $\varepsilon(Q(x, t))$ can be obtained by adding $\varepsilon_{1}(Q(x, t))$ and $\varepsilon_{2}(Q(x, t))$, which are independent;

4. the uncertainties affecting $Q^{\prime}(x, t)$ are independent and systematic errors are excluded;

5. $\varepsilon_{1}(Q(x, t))$ is a Gaussian random variable;

6. $\varepsilon_{2}(Q(x, t))$ is a binary random variable which can assume the values $+\left|\varepsilon_{2}(Q(x, t))\right|$ and $-\left|\varepsilon_{2}(Q(x, t))\right|$ with equal probability. It can be computed accordingly to an absolute additive error model (Eq. 4).

Assumptions 3) and 6) are conservative and may lead to an overestimation of the uncertainty. In order to better inspect this issue, Table 2 reports the amounts of $\left|\varepsilon_{2.1}\right|,\left|\varepsilon_{2.2}\right|$ and $\left|\varepsilon_{2.3}\right|$ averaged over the river reach, expressed as percentage of $Q(x, t)$. Given that $\varepsilon_{1}(Q(x, t))$ is equal to $5.3 \%$ at the $95 \%$ confidence level, one can see that it is negligible with respect to $\varepsilon_{2}(Q(x, t))$ and therefore the simplifying assumption 3$)$ is scarcely effective on the results.

The numerical analysis showed that the uncertainty induced by the extrapolation of the rating curve is dominating the other errors in high flow conditions, therefore making assumption 6) scarcely effective as well. In fact, previous contributions in hydrology (e.g. Rantz et al., 1982) recommend not extrapolating rating curves beyond a certain range. Nevertheless several hydrological applications are unavoidably based on flood flow observations (e.g. calibration and validation of rainfall-runoff models, flood frequency analysis, boundary conditions of flood inundation models) and therefore one needs to extrapolate the rating curve beyond the measurement range (Pappenberger et al., 2006). Given that the river reach under study is characterised by a very gentle slope (Table 1) the uncertainty induced by the presence 
of unsteady flow is also relevant in this test site (Table 2). Nevertheless, it is important to note that this latter source of error can be reduced by applying formulas proposed by scientific literature to approximate unsteady flow rating curves (e.g. Dottori et al., 2009). Finally, errors in the river flow measurements used to construct the rating curve and errors due to seasonal changes of roughness are not as significant.

\section{Conclusions}

Hydrological models often disregard the fact that river flow data are affected by a significant uncertainty. One of the main reasons is that modellers are often not able to quantitatively assess the reliability of rainfall or river discharge observations. This paper proposed a methodology to quantify the uncertainty that one may expect when river discharge observations are derived by applying the rating curve method. The methodology was applied to a reach of the Po River (Italy) by means of a 1-D hydraulic model. The overall error affecting river discharge observations averaged over the river reach under study was found to range from $6.2 \%$ to $42.8 \%$, at the $95 \%$ confidence level, with an average value of $25.6 \%$. Hence, errors in river discharge observations are significant and can heavily impact the output of hydrological and hydraulic studies. The results of the study are unavoidably associated with the considered test site. Nevertheless, it is important to note that the conditions of the Po River can be considered representative for many alluvial rivers in Europe. Also, the framework proposed in this paper can be easily applied to different river reaches.

Acknowledgements. The study has been partially supported by the Italian Government through its national grants to the programmes on "Advanced techniques for estimating the magnitude and forecasting extreme hydrological events, with uncertainty analysis". The authors are extremely grateful to the Po River Basin Authority (Autorità di Bacino del Fiume Po, Italy) allowing access to their topographic and hydrological data and to Ezio Todini, Guy Schumann and Tim Fewtrell for providing valuable suggestions. The editor Florian Pappenberger, the referees Hessel Winsemius and Geoff Pegram, as well as an anonymous referee, are also acknowledged for their useful and constructive comments.

Edited by: F. Pappenberger

\section{References}

Beven, K. J.: A manifesto for the equifinality thesis, J. Hydrol., 320, 18-36, 2006.

Castellarin, A., Di Baldassarre, G., Bates, P. D., and Brath, A.: Optimal cross-section spacing in Preissmann scheme 1D hydrodynamic models, J. Hydr. Eng., 135(2), 96-105, 2008.

Chow, V. T., Maidment, R. M., and Mays, L. W.: Applied Hydrology, McGrawHill, UK, 1988.

Clarke, R. T.: Uncertainty in the estimation of mean annual flood due to rating curve indefinition, J. Hydrol., 222, 185-190, 1999.
Franchini, M., Lamberti, P., and Di Giammarco, P.: Rating curve estimation using local stages, upstram discharge data and a simplified hydraulic model, Hydrol. Earth Syst. Sci., 3, 541-548, 1999, http:/www.hydrol-earth-syst-sci.net/3/541/1999/.

Dymond, J. R. and Christian, R.: Accuracy of discharge determined from a rating curve, Hydrological Sciences Journal, 27(4), 493504, 1982.

Dottori, F., Martina, M. L. V., and Todini E.: A dynamic rating curve approach to indirect discharge measurement, Hydrol. Earth Syst. Sci. Discuss., 6, 859-896, 2009,

http://www.hydrol-earth-syst-sci-discuss.net/6/859/2009/.

Herschy, R. W.: The evaluation of errors at flow measurement stations, International Symposium on Hydrometry, Koblenz, Germany, IAHS Pub. N. 99, 109-131, 1970.

Herschy, R. W.: The accuracy of existing and new methods of river gauging. Ph.D. thesis, Department of Geography, University of Reading, Reading, Berkshire, UK, 1975.

Herschy, R. W.: Accuracy in Hydrometry, edited by: Herschy, R. W., Wiley, New York, NY, USA, 353-397, 1978.

Hydrologic Engineering Center: Hydraulic Reference Manual, US Army Corps of Engineers, Davis, California, USA, 2001

European ISO EN Rule 748, Measurement of liquid flow in open channels - velocity-area methods, Reference number ISO 748:1997 (E), International Standard, 1997.

Götzinger, J., and Bárdossy, A.: Generic error model for calibration and uncertainty estimation of hydrological models, Water Resour,. Res., 44, W00B07, doi:10.1029/2007WR006691, 2008.

Horritt, M. S. and Bates P. D.: Evaluation of 1-D and 2-D models for predicting river flood inundation, J. Hydrol., 268, 87-99, 2002.

Léonard, J., Mietton, M., Najib, H., and Gourbesville, P.: Rating curve modelling with Manning's equation to manage instability and improve extrapolation, Hydrol. Sci. J., 45(5), 739-750, 2000.

Liu, Y., Freer, J., Beven, K., and Matgen, P.: Towards a limits of acceptability approach to the calibration of hydrological models: Extending observation error, J. Hydrol., 367(1-2), 93-103, 2009.

Maione, U., Mignosa P., and Tomirotti M.: Regional Estimation Model of Synthetic Design Hydrographs, International Journal of River Basin Management, 12, 151-163, 2003.

Montanari, A.: What do we mean by "uncertainty"? The need for a consistent wording about uncertainty assessment in hydrology, Hydrol. Proc., 21, 841-845, 2007.

Montanari, A. and Brath, A.: A stochastic approach for assessing the uncertainty of rainfall-runoff simulations, Water Resour. Res., 40, W01106, doi:10.1029/2003WR002540, 2004.

Montanari, A. and Grossi G.: Estimating the uncertainty of hydrological forecasts: A statistical approach, Water Resour. Res., 44, W00B08, doi:10.1029/2008WR006897, 2008.

Pappenberger, F., Matgen P., Beven K. J., Henry J. B., Pfister L., and de Fraipont P.: Influence of uncertain boundary conditions and model structure on flood inundation predictions, Adv. Water Resour., 29, 1430-1449, 2006.

Pelletier, M. P.: Uncertainties in the determination of river discharge: a literature review, Can. J. Civ. Eng., 15, 834-850, 1987.

Petersen-Øverleir, A.: Accounting for heteroscedasticity in rating curve estimates, J. Hydrol., 292, 173-181, 2004.

Preissmann, A.: Propagation of translatory waves in channels and rivers (in French), in: Proc. First Congress of French Association for Computation (AFCAL), Grenoble, France, 433-442, 1961.

Rantz, S. E. et al.: Measurement and computation of streamflow, 
US Geological Survey, Water Supply Paper number 2175, online available at: http://water.usgs.gov/pubs/wsp/wsp2175/, 1982.

Sivapalan, M., Takeuchi, K., Franks, S. W., Gupta, V. K., Karambiri, H., Lakshmi, V., Liang, X., McDonnell, J. J., Mendiondo, E. M., O’Connell, P. E., Oki, T., Pomeroy, J. W., Schertzer, D., Uhlenbrook, S., and Zehe, E.: IAHS Decade on Predictions in Ungauged Basins (PUB), 2003-2012: Shaping an exciting future for the hydrological sciences, Hydrol. Sci. J., 48, 857-880, 2003.

Schmidt, A. R.: Analysis of stage-discharge relations for openchannel flow and their associated uncertainties, Urbana, University of Illinois, 328 pp., 2002.
Young, P. C., Leedal, D., and Beven, K. J., and Szczypta, C.: Reduced order emulation of distributed hydraulic models. In Proceedings 15th IFAC Symposium on System Identification SYSID09, St. Malo, France, 2009.

Yu, B.: A systematic over-estimation of flows, J. Hydrol., 233, 258262, 2000.

World Meteorological Organisation: Guide to Hydrological Practice, WMO Pubbl. no. 168, 1994. 